Article

\title{
How Individuals' Characteristics Influence Their Wellbeing through Physical Activity and Sport: Motivated by the Signaling Theory
}

\author{
Gang Xiao ${ }^{1}$, Qing Yi ${ }^{2,3,4, *}$ and Jinyi Zhou ${ }^{5, *}$ \\ 1 School of Economics and Management, Tsinghua University, Beijing 100084, China; \\ xiaog.15@sem.tsinghua.edu.cn \\ 2 School of Physical Education and Sport Training, Shanghai University of Sport, Shanghai 200438, China \\ 3 Shanghai Key Lab of Human Performance, Shanghai University of Sport, Shanghai 200438, China \\ 4 Key Laboratory of Diagnosis \& Analysis of Skills \& Tactics in Sports, Shanghai University of Sport, \\ Shanghai 200438, China \\ 5 Department of Business Administration, Donlinks School of Economics and Management, \\ University of Science and Technology Beijing, Beijing 100083, China \\ * Correspondence: yiqing@sus.edu.cn (Q.Y.); jinyi@ustb.edu.cn (J.Z.)
}

Received: 27 April 2020; Accepted: 21 May 2020; Published: 22 May 2020

check for updates

\begin{abstract}
Sports activities engagement is a sustainable lifestyle that can signal that individuals have the potential to become successful. The lifetime wellbeing that comes from participating in sports activities results in a general and global policy agenda encouraging populations to be part of it. However, prior studies have seldom tested how individuals' characteristics influence their wellbeing through sports activities engagement from a lifetime perspective. In the current study, based on the conservation of resources and signaling theories, we suggest that with a high level of personal control and self-esteem, individuals will proactively maintain a good lifestyle by engaging in more sports activities. Moreover, this engagement is not only good for these individuals' physical and mental health, but will also bring them much more life satisfaction than others. A large and representative sample with 12,686 participants collected from over 35-year surveys across different social classes in the United States is used to test our hypotheses. The results indicate that individuals' characteristics will indeed influence their wellbeing, even after 40 years of age, by changing their sports activities engagement, which includes both light activities such as walking and vigorous activities such as running and swimming. Potential theoretical contributions and policy implications are also proposed.
\end{abstract}

Keywords: sport; wellbeing; health; individuals' characteristics; signaling theory

\section{Introduction}

Health is a cherished resource that may bring many benefits to individuals. For example, a good health condition can serve as a signal, sending the market the message that such individuals can bring organizations more competitive advantages. Many organizations will care about newcomers' health conditions when recruiting new employees. Some universities find that students with better health conditions are more likely to become successful in the future. Health is actually one of the most fundamental resources for individuals not only in terms of the simple absence of disease, but also a more general wellbeing that includes physical, mental and social aspects $[1,2]$.

Many studies from different research areas have already indicated that the most efficient way for individuals to maintain or improve their general wellbeing is to proactively engage in sports activities regularly $[1,3,4]$. Several studies found physical and psychological benefits of regularly engaging in sports activities [4-6]; for example, a study found that regularly engaging in sports activities can 
intensively reduce the risks of suffering physical and mental illnesses, such as obesity [5]. Moreover, engaging in sports activities is an ideal way for individuals to receive more social benefits, and to convey to the labor market their physical advantages. For example, Georgian et al. [1] indicate that sports activities could help individuals to establish new relationships, and therefore maintain or improve the social aspect of their wellbeing by enjoying exercise together, while some sports such as football, basketball or even group jogging can only be completed by a group of people. Winzer et al. [7] indicated that physical activity could effectively prevent primary cardiovascular disease, while Loprinzi et al. [8] demonstrated that physical activity has a preventive effect on memory impairment. As more and more individuals become aware that sports activities can reduce their informational asymmetry by signaling a good quality of life, wider society will also benefit from the enrollment of organized sports activities, since they can let people with common interests gather together and develop a strong sense of cooperation, if individuals can have such information [6]. In this way, individuals will feel and actually receive more social support from others, which is crucial for social aspects of wellbeing, such as life satisfaction.

According to the conservation of resources theory [9], individuals have relatively limited resources, such as energy and time, to deal with critical tasks such as work and study in their daily lives. The condition of resource depletion is detrimental for people's general wellbeing, in terms of physical and psychological aspects. However, individuals can store and even proactively invest more resources from the environment [10]. For example, seeking support from families can always help individuals to deal with the difficulties of their work. Based on this theory, sports activities can be another useful tool for individuals to accumulate resources in order to prepare for the obstacles they encounter. Moreover, since individuals have a self-consistency tendency [11], they will maintain consistent life habits during their whole lifetime. This means that a good habit of sports activities engagement could be a lifetime resource accumulation strategy for individuals to maintain a healthy condition. In the current study, we suggest that the habit of engaging in sports activities should influence lifetime wellbeing.

However, whether regularly engaging in sports activities can influence individuals' wellbeing across various life spans is still unknown. Besides, tests have been undertaken on both individuals' objective wellbeing, such as physical and mental health, and subjective wellbeing such as life satisfaction, which have shown they are impacted by this life habit [12,13]. Thus, in the current study, based on the conservation of resources theory, we suggest that regularly engaging in sports activities could help individuals to have a better lifetime wellbeing and subjective life satisfaction than others.

Hypothesis 1a (H1a). Regularly engaging in sports activities can positively influence individuals' lifetime physical and mental health.

Hypothesis 1b (H1b). Regularly engaging in sports activities can positively influence individuals' life satisfaction.

Researchers have tried to identify individual differences that are associated with participation in regular sports activities. Some kinds of big-five personalities, such as conscientiousness, extraversion, openness and neuroticism, are shown to predict sports habits [14]. For example, some researchers find that a high level of extraversion and conscientiousness or a low level of neuroticism will lead to more physical activities than others [15,16]. Moreover, a core component of conscientiousness-industriousness and the activity, a core component of extraversion-is always selected as the most critical predictor of sports activities [17]. Particularly, some recent studies started to focus on sports activities across different life spans, and a high level of conscientiousness led to a faster initial walking speed and a slower decline.

All in all, prior studies keep finding that there are some inherent and stable individual differences influencing individuals' sports habits and wellbeing. However, few of these studies have been clearly linked to the complicated relationships among individual differences, sports activities and wellbeing. Moreover, few prior studies have investigated whether individuals' sports habits will be consistently influenced by their individual differences across different life spans, as well as how these habits 
influence their lifetime wellbeing after retirement [18]. Therefore, in the current study, we aim to establish the theoretical model linking individuals' characteristics to their lifetime wellbeing through sports engagement.

In the current study, we also find the predictive validity of two other characteristics, personal control and self-esteem, based on the signaling theory [19]. Personal control can be defined as a characteristic that describes to what extent individuals feel that they have the control of the forces impacting their lives [20]. Personal control can reside within individuals' self-concept to enhance their belief that they can control the environment, so they will become formidable towards the strains through making efforts to prepare for obstacles. Thus, personal control can urge individuals to maintain good habits for potential upcoming difficulties. Sports activities, as one feasible way for individuals to reserve their valuable resources, will be employed if individuals hold a high level of personal control. Moreover, signaling theories suggest that individuals can use many kinds of information clues to reduce informational asymmetry [21]. Sports activities may serve as an efficient clue, indicating that such individuals generally hold enough physical and mental resources dealing with the obstacles during their career, reducing the concerns from relevant stakeholders such as employers. Therefore, we suggest that the high level of personal control will lead to more regular sports activities that can benefit individuals' wellbeing.

Hypothesis 2a (H2a). There will be positive relationships between personal control and sports activities engagement.

Hypothesis $\mathbf{2 b} \mathbf{b} \mathbf{H} \mathbf{2 b})$. Sports activities engagement will mediate the relationship between personal control and lifetime wellbeing (physical, mental health and subjective life satisfaction).

Similarly, self-esteem could be another kind of important psychological resource. Self-esteem is individuals' overall evaluation of themselves [22], and the feelings that they are objects in a world of meaningful actions [23]. According to prior studies, self-esteem can help individual mobilize resources to solve potential difficulties during their daily lives [24]. Moreover, individuals with a high level of self-esteem are more likely to have good self-regulation [25], and are generally more persistent when encountering failures [26]. Therefore, self-esteem will lead individuals to maintain good life habits such as sports activities engagement, and thus enhance their wellbeing as a result (see Figure 1 for the whole theoretical model). Therefore, the next two hypotheses will be:

Hypothesis 3a (H3a). Self-esteem will positively affect sports activities engagement.

Hypothesis $\mathbf{3 b} \mathbf{b} \mathbf{H} 3 \mathbf{b})$. Sports activities engagement will mediate the relationship between self-esteem and lifetime wellbeing (physical, mental health and subjective life satisfaction).

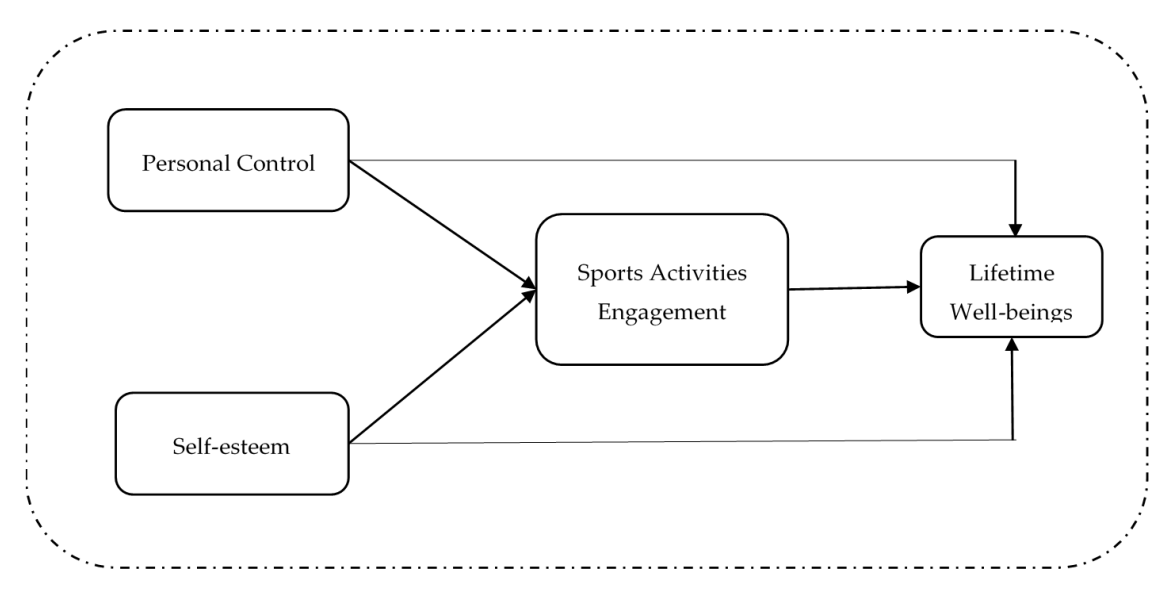

Figure 1. Whole Theoretical Model. 


\section{Methods}

\subsection{Sample Descriptions}

We test the theoretical model through a sample from the National Longitudinal Survey of Youth 1979 (i.e., NLSY 79). This is a representative sample that tracks participants from the United States. This project comprehensively covers different social classes, since it has collected many variables of labor economic, sociology, psychological and health management for over 35 years. Therefore, it is suitable for us to test the model we propose. The whole cohort is interviewed annually from 1979 to 1994, and biennially after 1994 until 2016.

A multi-wave data collection strategy is used here, and four waves of data from this project are collected. All participants' demographic information such as age, gender, education, race, poverty status, their parents' health and education are collected at Wave 1 in 1979. Their self-esteem is collected in 1980 (Wave 2). Their sports activities engagement is collected in 1998 (Wave 3), and their subjective life satisfaction is collected in 2014 (Wave 4). Their mental and physical health information is collected across numerous years from 1998 to 2014, whenever the participants reached 40 years old. This method can ensure the completeness of data collection. Moreover, we collected variables from these specific years because these relevant variables were only measured in those years. Participants' identification numbers help us track them after several years. That means the same cohort of participants are surveyed for over 30 years. Besides, considering that individuals will generally hold a consistent trend of their life habits, such as engaging in physical activities [27], the data-collection strategy we use is appropriate to be used. From Table 1, we can figure that most participants entered high school in 1979, their average age in 1979 is $17.90(S D=2.31)$, and the range of their age was from 14 to 22 that year. The 12,686 participants comprised 6403 men $(50.47 \%)$ and 6283 women $(49.53 \%)$.

Table 1. Descriptive Statistics of Main Variables.

\begin{tabular}{|c|c|c|c|c|c|c|}
\hline Variables & Category & Size & Mean & Standard Deviation & Range & Percentage \\
\hline Age & & 12,686 & 17.90 & 2.31 & $14-22$ & \\
\hline \multirow{2}{*}{ Gender } & Male & 6403 & & & & $50.47 \%$ \\
\hline & Female & 6283 & & & & $49.53 \%$ \\
\hline Education & & 12.534 & 10.50 & 2.29 & $0-20$ & \\
\hline \multirow{3}{*}{ Race } & White & 2002 & & & & $15.78 \%$ \\
\hline & Black & 3174 & & & & $25.02 \%$ \\
\hline & Other & 7510 & & & & $59.20 \%$ \\
\hline \multirow{2}{*}{ Poverty Status } & Not Poor & 7966 & & & & $80.54 \%$ \\
\hline & Poor & 1925 & & & & $19.46 \%$ \\
\hline Mother's Education & & 11,878 & 10.87 & 3.17 & $0-20$ & \\
\hline Father's Education & & 10,880 & 10.85 & 3.93 & $0-20$ & \\
\hline \multirow{2}{*}{ Mother's Health } & Not Health & 3275 & & & & $53.87 \%$ \\
\hline & Health & 2804 & & & & $46.13 \%$ \\
\hline \multirow{2}{*}{ Father's Health } & Not Health & 2426 & & & & $55.94 \%$ \\
\hline & Health & 1911 & & & & $44.06 \%$ \\
\hline Personal Control & & 8938 & 22.04 & 3.27 & $7-28$ & \\
\hline Self-Esteem & & 11,992 & 22.37 & 4.13 & $6-30$ & \\
\hline \multirow{2}{*}{ Sports Activity } & Light & 6352 & 4.03 & 1.26 & $1-5$ & \\
\hline & Vigorous & 6351 & 2.77 & 1.57 & $1-5$ & \\
\hline \multirow{2}{*}{ Wellbeing } & Physical and Mental Health & 8450 & 3.64 & 1.01 & $1-5$ & \\
\hline & Life Satisfaction & 7042 & 5.79 & 1.37 & $1-7$ & \\
\hline
\end{tabular}

\subsection{Measures}

Wellbeing. We use two variables that represent the wellbeing: physical and mental health; and life satisfaction. (1) For physical and mental health, participants' physical and mental health is measured 
by one item: "In general, how is your health?" We use a general measure of participants' physical and mental health information, considering participants themselves know their own health condition best. This health information is collected whenever they reached the age of 40 years old. A five-point Likert scale is used, with " 1 " indicating "Excellent" and " 5 " indicating "Poor". A reversed score of this item is used. (2) For Life Satisfaction: participants' subjective life satisfaction is measured by one item: "How dissatisfied or satisfied are you with your life overall". A seven-point Likert scale is used, with "1" indicating "not at all satisfied" and "7" indicating "completely satisfied".

Personal Control. The Pearlin Mastery Scale is used in the current study to measure the personal control according to prior studies [20]. This scale comprises seven items, and is used to measure participants' self-concept and the extent to which they will perceive themselves in control of forces that can significantly influence their lives. A sample item is: "No way I can solve some of the problems I have". Negatively recorded items are reversed, and the four-point Likert scale is used. Strongly disagree is measured with " 1 ", and strongly agree is measured by " 4 ". The sum score of these seven items is used. This scale's Cronbach's $\alpha$ is 0.79 .

Self-esteem. The Rosenberg Self-esteem Scale is used here to measure self-esteem in 1980. This scale comprises 10 items and is adapted from Rosenberg [28], and measures participants' self-evaluation individuals make about themselves. One sample item is "I am a person of worth", for which a four-point Likert scale is used, with " 0 " indicating "Strongly Agree" and " 3 " indicating "Strongly Disagree". The sum score of these 10 items is used. The Cronbach's $\alpha$ of this scale is 0.84 .

Sports Activities Engagement. We use two kinds of exercise to represent participants' sports activities engagement. The light exercise item can measure how often participants join in light activities such as walking, dancing, gardening and bowling. The vigorous activity item measures how often they participate in vigorous activities or sports such as running, aerobics, swimming and bicycling. A five-point Likert scale is used, with " 1 " indicating "three times or more each week" and " 5 " indicating "never". The reversed scores of these two items are used in the study.

Control variables. All participants' age, gender, education, and race information are collected in 1979 , and treated as control variables. Race is measured by indicating whether participants belong to the "Hispanic", "Black" or "non-Black and non-Hispanic" race groups. Thus, two dummy variables are created to indicate which group participants belong to. Race 1 is designated to 1 when such a participant belongs to the "Hispanic" group, while Race 2 is 1 when the participant belongs to the "Black" group. Their education is measured by the level of education achieved by these participants in 1979, which takes 21 values ranging from 0 (no education) to 20 (post baccalaureate graduate). Parents' educations are measured by exactly the same scale as used for measuring the education of participants. Twenty-one values ranging from 0 (no education) to 20 (post baccalaureate graduate) are used to measure participants' mother and father's levels of education in 1979 as well. Participants' poverty status is measured by using their familial poverty compared to the income guidelines of the US Department of Health and Human Services from 1980. Their parents' health conditions are measured by asking whether they have any major health problems.

\subsection{Statistical Analyses}

Several statistical methods are employed in this study. For example, the hierarchical regression model with the ordinary least square method is used to test all hypotheses. The bootstrapping method is also used to test the mediating effects. Bootstrapping is one kind of resampling strategies for hypothesis testing. This method could calculate the statistic of interest in multiple resamples of the data set, without any assumptions about the shape of the sampling distribution. Descriptive statistics of all variables in this study are shown in Table 1, and correlations between each pair of variables are shown in Table 2. From this table, we do not find highly correlated constructs, suggesting that there is no serious multicollinear problem. 
Table 2. Correlations of Main Variables.

\begin{tabular}{|c|c|c|c|c|c|c|c|c|c|c|c|c|c|c|c|}
\hline Variables & 1 & 2 & 3 & 4 & 5 & 6 & 7 & 8 & 9 & 10 & 11 & 12 & 13 & 14 & 15 \\
\hline 1. Age & - & & & & & & & & & & & & & & \\
\hline 2. Gender & 0.01 & - & & & & & & & & & & & & & \\
\hline 3. Education & + & $0.05^{* * *}$ & - & & & & & & & & & & & & \\
\hline 4. Race1 & $-0.05^{* * *}$ & 0.00 & $-0.12 * * *$ & - & & & & & & & & & & & \\
\hline 5. Race2 & $-0.04 * * *$ & 0.00 & $-0.04 * * *$ & $-0.25 * * *$ & - & & & & & & & & & & \\
\hline 6. Poverty Status & $-0.09 * * *$ & $0.05^{* * *}$ & $-0.15^{* * *}$ & $0.05^{* * *}$ & $0.21^{* * *}$ & - & & & & & & & & & \\
\hline 7. Mother's Education & $0.04 * * *$ & $-0.02 *$ & $0.25^{* * *}$ & $-0.40 * * *$ & -0.01 & $-0.23 * * *$ & - & & & & & & & & \\
\hline 8. Father's Education & 0.03 ** & -0.01 & $0.23 * * *$ & $-0.29 * * *$ & $-0.09 * * *$ & $-0.21^{* * *}$ & $0.65^{* * *}$ & - & & & & & & & \\
\hline 9. Mother's Health & -0.02 & $-0.10^{* * *}$ & 0.02 & $-0.05 * * *$ & $-0.04 * *$ & $-0.04 * *$ & $0.12 * * *$ & $0.10^{* * *}$ & - & & & & & & \\
\hline 10. Father's Education & 0.00 & $-0.07^{* * *}$ & -0.01 & 0.00 & -0.01 & -0.03 & $0.06^{* * *}$ & $0.07^{* * *}$ & $0.27^{* * *}$ & - & & & & & \\
\hline 11. Personal Control & $-0.07^{* * *}$ & $-0.02 *$ & $0.08^{* * * *}$ & -0.03 ** & $-0.05 * * *$ & $-0.13 * * *$ & $0.16^{\text {*** }}$ & $0.16^{* * *}$ & $0.08^{* * *}$ & 0.03 & $(0.79)$ & & & & \\
\hline 12. Self-Esteem & $0.18^{* * *}$ & $-0.04 * * *$ & $0.29^{* * *}$ & $-0.08 * * *$ & 0.01 & $-0.14 * * *$ & $0.21 * * *$ & $0.20^{* * *}$ & $0.07 * * *$ & 0.03 & $0.31^{* * *}$ & $(0.84)$ & & & \\
\hline 13. Light Activity & 0.00 & 0.00 & $0.09^{* * *}$ & $-0.03 * *$ & $-0.11 * * *$ & $-0.08 * * *$ & $0.14^{* * *}$ & $0.14^{* * *}$ & $0.05^{* *}$ & 0.01 & $0.14^{* * *}$ & $0.13 * * *$ & - & & \\
\hline 14. Vigorous Activity & $-0.06^{* * *}$ & $-0.19 * * *$ & $0.05^{* * *}$ & $-0.04 * *$ & $-0.09 * * *$ & $-0.09 * * *$ & $0.16^{* * *}$ & $0.17^{* * *}$ & $0.09 * * *$ & 0.03 & $0.16^{* * *}$ & $0.13^{* * *}$ & $0.38^{* * *}$ & - & \\
\hline 15. Physical and Mental Health & $0.03 *$ & $-0.06^{* * *}$ & $0.12 * * *$ & $-0.05 * * *$ & $-0.08 * * *$ & $-0.09 * * *$ & $0.16^{\text {*** }}$ & $0.15^{* * *}$ & $0.13^{* * *}$ & $0.10^{* * *}$ & $0.23 * * *$ & 0.19 *** & $0.15^{* * *}$ & $0.23 * * *$ & - \\
\hline 16. Life Satisfaction & 0.02 & 0.00 & 0.01 & $0.05^{* * *}$ & 0.00 & 0.02 & $-0.04 * *$ & $-0.06^{* * *}$ & $0.07^{* * *}$ & $0.04 *$ & $0.15^{* * *}$ & $0.08^{* * *}$ & 0.02 & $0.03 *$ & $0.16^{* * *}$ \\
\hline
\end{tabular}




\section{Results}

The hierarchical regression results are shown in Table 3. From Model 7 in Table 3, we can see that the light activity has a positively significant relationship with physical and mental health $(\beta=0.05$, $p<0.01)$, and so too does vigorous activity $(\beta=0.12, p<0.001)$. Therefore, Hypothesis 1a is supported.

To test Hypothesis $1 \mathrm{~b}$, we also test the relationship between sports activities engagement and life satisfaction. From Model 11 in Table 3, we find that the vigorous activity has a positive relationship with life satisfaction $(\beta=0.06, p<0.05)$. However, the relationship between light activity and life satisfaction is not significant $(\beta=0.02)$. Thus, Hypothesis $1 \mathrm{~b}$ is partially supported.

From Model 2 and Table 3, we conclude that personal control has significant relationships with light $(\beta=0.03, p<0.001)$ and vigorous activity $(\beta=0.04, p<0.001)$, while self-esteem also has significant relationships with light $(\beta=0.04, p<0.001)$ and vigorous activity $(\beta=0.03, p<0.01)$. Therefore, Hypotheses $2 \mathrm{a}$ and $3 \mathrm{a}$ are supported.

Moreover, following Baron et al. [29], several steps were used to test Hypotheses $2 b$ and $3 b$. We first regress independent variables to mediators and find a significant relationship (personal control to light activity: $\beta=0.03, p<0.001$; personal control to vigorous activity: $\beta=0.04, p<0.001$; self-esteem to light activity: $\beta=0.02, p<0.05$; and self-esteem to vigorous activity: $\beta=0.03, p<0.01$ ). Then, we regress mediators to dependent variables and find that most relationships are significant (light activity to physical and mental health: $\beta=0.05, p<0.01$; light activity to life satisfaction: $\beta=0.02$, not significant; vigorous activity to physical and mental health: $\beta=0.12, p<0.001$; and vigorous activity to life satisfaction: $\beta=0.06, p<0.05$ ). We then regress independent variables to dependent variables, and found that most relationships are significant (personal control to physical and mental health: $\beta=0.05, p<0.001$; personal control to life satisfaction: $\beta=0.06, p<0.001$; self-esteem to physical and mental health: $\beta=0.03, p<0.001$; and self-esteem to life satisfaction: $\beta=0.03, p<0.001$ ). Lastly, when we enter the mediator, we find that relationships between independent variables and dependent variables become less significant (personal control to physical and mental health: $\beta=0.04$, $p<0.001$; personal control to life satisfaction: $\beta=0.06, p<0.001$; self-esteem to physical and mental health: $\beta=0.02, p<0.001$; and self-esteem to life satisfaction: $\beta=0.03, p<0.01$ ). Therefore, Hypotheses $2 \mathrm{~b}$ and $3 \mathrm{~b}$ are generally supported.

A bootstrapping method with 3000 re-samplings is used here to test two mediating effects (Hypotheses 2b and 3b) [30,31]. From Table 4, we discover that most indirect effects are significant. For example, the indirect effect of light activity between personal control and physical and mental health is significant, and the 95\% confidence interval excludes 0 (indirect effect $=0.003, p<0.001,95 \%$ confidence interval $=[0.002,0.005])$. The indirect effect of vigorous activity between personal control and physical and mental health is also significant, and the $95 \%$ confidence interval excludes 0 (indirect effect $=0.009, p<0.001,95 \%$ confidence interval $=[0.007,0.01])$. Therefore, confirming prior analyses, Hypotheses $2 \mathrm{~b}$ and $3 \mathrm{~b}$ are generally supported.

In conclusion, all six hypotheses are supported. We find that personal control and self-esteem are positively related to sports activities engagement, and regularly engaging in sports activities can really improve individuals' lifetime wellbeing, including health and life satisfaction. Sports activities engagement significantly mediates the relationship between individuals' characteristics and their wellbeing. 
Table 3. Hierarchical Regressions.

\begin{tabular}{|c|c|c|c|c|c|c|c|c|c|c|c|c|}
\hline \multirow{2}{*}{ Variables } & \multicolumn{2}{|c|}{ Light Activity } & \multicolumn{2}{|c|}{ Vigor Activity } & \multicolumn{4}{|c|}{ Physical and Mental Health } & \multicolumn{4}{|c|}{ Life Satisfaction } \\
\hline & Model 1 & Model 2 & Model 3 & Model 4 & Model 5 & Model 6 & Model 7 & Model 8 & Model 9 & Model 10 & Model 11 & Model 12 \\
\hline Control Variables & & & & & & & & & & & & \\
\hline Age & $-0.07(0.02)^{* * *}$ & $-0.06(0.02) * *$ & $-0.10(0.03)^{* * *}$ & $-0.08(0.03) * *$ & $-0.06(0.01)^{* * *}$ & $-0.04(0.01) * *$ & $-0.05(0.02)^{* *}$ & $-0.04(0.02) *$ & $-0.01(0.02)$ & $0.01(0.02)$ & $0.01(0.03)$ & $0.03(0.03)$ \\
\hline Gender & $-0.01(0.06)$ & $0.01(0.06)$ & $-0.46(0.07)^{* * *}$ & $-0.44(0.07)^{* * *}$ & $-0.12(0.04) * *$ & $-0.09(0.04) *$ & $-0.02(0.05)$ & $0.01(0.05)$ & $-0.05(0.05)$ & $-0.02(0.05)$ & $-0.08(0.07)$ & $-0.06(0.07)$ \\
\hline Education & $0.10(0.03)^{* * *}$ & $0.08(0.03)^{* *}$ & $0.10(0.03)^{* *}$ & $0.06(0.03)^{+}$ & $0.11(0.02)^{* * *}$ & $0.08(0.02)^{* * *}$ & $0.10(0.02)^{* * *}$ & $0.07(0.02)^{* * *}$ & $0.04(0.03)^{+}$ & $0.00(0.03)$ & $0.03(0.03)$ & $0.01(0.03)$ \\
\hline Race Dummy 1 & $-0.01(0.08)$ & $-0.01(0.08)$ & $-0.02(0.11)$ & $-0.02(0.11)$ & $-0.12(0.05) *$ & $-0.16(0.05)$ ** & $-0.13(0.06) *$ & $-0.15(0.06) *$ & $0.15(0.08)^{+}$ & $0.10(0.08)$ & $0.14(0.10)$ & $0.11(0.10)$ \\
\hline Race Dummy 2 & $-0.29(0.07)^{* * * *}$ & $-0.32(0.08)^{* * *}$ & $-0.39(0.10)^{* * * *}$ & $-0.41(0.10)^{* * * *}$ & $-0.20(0.05)^{* * *}$ & $-0.23(0.05)^{* * *}$ & $-0.17(0.06)^{* *}$ & $-0.19(0.06)^{* * *}$ & $-0.00(0.07)$ & $-0.07(0.07)$ & $-0.02(0.09)$ & $-0.11(0.09)$ \\
\hline Poverty Status & $0.00(0.09)$ & $-0.02(0.09)$ & $0.05(0.11)$ & $0.06(0.11)$ & $0.07(0.06)$ & $0.08(0.06)$ & $0.05(0.07)$ & $0.06(0.07)$ & $-0.01(0.09)$ & $0.03(0.09)$ & $-0.10(0.11)$ & $-0.06(0.11)$ \\
\hline Mother's Education & $0.04(0.01)^{* * *}$ & $0.04(0.01)^{* * *}$ & $0.02(0.02)$ & $0.02(0.02)$ & $0.02(0.01)^{*}$ & $0.01(0.01)$ & $0.01(0.01)$ & $0.01(0.01)$ & $-0.01(0.01)$ & $-0.02(0.01)$ & $-0.01(0.02)$ & $-0.02(0.02)$ \\
\hline Father's Education & $0.01(0.01)$ & $0.00(0.01)$ & $0.03(0.01)^{*}$ & $0.03(0.01)^{*}$ & $0.01(0.01)$ & $0.00(0.01)$ & $0.00(0.01)$ & $-0.00(0.01)$ & $-0.00(0.01)$ & $-0.01(0.01)$ & $-0.00(0.01)$ & $-0.09(0.07)$ \\
\hline Mother's Health & $0.03(0.06)$ & $0.00(0.06)$ & $0.13(0.06)+$ & $0.10(0.08)+$ & $0.16(0.04)^{* * *}$ & $0.14(0.04)^{* * *}$ & $0.14(0.05)^{* *}$ & $0.13(0.05)^{* *}$ & $0.21(0.06)^{* * * *}$ & $0.16(0.06)^{* *}$ & $0.19(0.07)^{* *}$ & $0.14(0.07)^{*}$ \\
\hline $\begin{array}{l}\text { Father's Health } \\
\text { Predictor }\end{array}$ & $0.05(0.06)$ & $0.05(0.06)$ & $0.06(0.08)$ & $0.05(0.08)$ & $0.09(0.04)^{*}$ & $0.09(0.04)^{*}$ & $0.12(0.05)^{* *}$ & $0.12(0.05)$ * & $0.06(0.06)$ & $0.09(0.06)$ & $0.08(0.07)$ & $0.09(0.07)$ \\
\hline Personal Control & & $0.03(0.01)^{* * *}$ & & $0.04(0.01)^{* * *}$ & & $0.05(0.01)^{* * *}$ & & $0.04(0.01)^{* * *}$ & & $0.06(0.01)^{* * *}$ & & $0.06(0.01) * * *$ \\
\hline Self-Esteem & & $0.02(0.01) *$ & & $0.03(0.01) * *$ & & $0.03(0.01)^{* * *}$ & & $0.02(0.01)^{* * *}$ & & $0.03(0.01)^{* * *}$ & & $0.03(0.01)^{* * *}$ \\
\hline Light Activity & & & & & & & $0.05(0.02) * *$ & $0.04(0.02) *$ & & & $0.02(0.03)$ & $0.00(0.03)$ \\
\hline Vigorous Activity & & & & & & & $0.12(0.02)^{* * *}$ & $0.11(0.02)^{* * *}$ & & & $0.06(0.02)^{*}$ & $0.04(0.02)+$ \\
\hline
\end{tabular}

$$
\text { Note: }+p<0.10 ;{ }^{*} p<0.05 ;{ }^{* *} p<0.01 ;{ }^{* * *} p<0.001 \text {. }
$$

Table 4. Results of Bootstrapping Analyses with 3000 re-samplings.

\begin{tabular}{|c|c|c|c|c|c|c|c|c|}
\hline Independent Variables & Mediators & Dependent Variables & Indirect Effect & $S E$ & LL CI & UL CI & $Z$ & $p$ Value (Two-Tailed) \\
\hline \multirow{4}{*}{ Personal Control } & \multirow[b]{2}{*}{ Light Activity } & Physical and Mental Health & 0.003 & 0.001 & 0.002 & 0.005 & $4.55^{* * *}$ & 0.00 \\
\hline & & Life Satisfaction & 0.001 & 0.001 & -0.001 & 0.002 & 0.74 & 0.46 \\
\hline & \multirow[b]{2}{*}{ Vigorous Activity } & Physical and Mental Health & 0.009 & 0.001 & 0.007 & 0.01 & $7.83^{* * *}$ & 0.00 \\
\hline & & Life Satisfaction & 0.002 & 0.001 & 0.001 & 0.004 & $2.52 *$ & 0.01 \\
\hline \multirow{4}{*}{ Self-Esteem } & \multirow[b]{2}{*}{ Light Activity } & Physical and Mental Health & 0.002 & 0.001 & 0.002 & 0.003 & $4.52 * * *$ & 0.00 \\
\hline & & Life Satisfaction & 0.000 & 0.001 & 0.000 & 0.001 & 0.77 & 0.44 \\
\hline & \multirow{2}{*}{ Vigorous Activity } & Physical and Mental Health & 0.005 & 0.001 & 0.004 & 0.007 & $6.19 * * *$ & 0.00 \\
\hline & & Life Satisfaction & 0.001 & 0.001 & 0.001 & 0.002 & $2.52 *$ & 0.01 \\
\hline
\end{tabular}




\section{Discussion}

\subsection{Theoretical Contributions}

In the current study, we establish significant relationships among individuals' characteristics, their sports activities engagement and their lifetime wellbeing. Six hypotheses are proposed and tested. Hypothesis 1a proposes that regularly engaging in sports activities can positively influence individuals' lifetime physical and mental health, and Hypothesis $1 \mathrm{~b}$ indicates that regularly engaging in sports activities can positively influence individuals' life satisfaction. Hypothesis 2a proposes that there will be positive relationships between personal control and sports activities engagement, while Hypothesis $2 b$ states that sports activities engagement will mediate the relationship between personal control and lifetime wellbeing (physical, mental health and subjective life satisfaction). Hypothesis 3a suggests that self-esteem will positively affect sports activities engagement, and Hypothesis $3 b$ proposes that sports activities engagement will mediate the relationship between self-esteem and lifetime wellbeing (physical, mental health and subjective life satisfaction).

These findings have some crucial contributions to both the conservation of resources and signaling theories. First, we link individuals' sports activities to their lifetime wellbeing. We suggest that individuals will hold independent and consistent sports activities engagement or habits that will influence their lifetime wellbeing. Second, we differentiate kinds of wellbeing to incorporate both physical and mental aspects and social aspects. We especially propose that sports activities are not only good for avoiding physical or mental problems, but also can help them to receive more resources from the environment, and help improve their overall life satisfaction. Moreover, we emphasize the importance of personal characteristics, and link it towards individuals' life habits and terminal wellbeing across various life stages (from adolescence to middle age). This result tells us that individual differences such as personality can implicitly but consistently change individuals' behavioral scripts, and their influences will last for a long time, even after decades.

Moreover, another important contribution of this paper is that we identify two specific characteristics, personal control and self-esteem, as the core predictors in our theoretical model. The common meanings underlying these two characteristics are that individuals who have a high level of personal control and self-esteem will have a great sense that they will control the forces which will significantly impact their lives. Besides, with a high level of these two characteristics, individuals will respect nature and themselves, so they will maintain good life habits in preparation for upcoming difficulties, according to the conservation of resources theory.

Last but not least, the remaining contribution of this paper could be that we use the lifetime perspective to tell the story. We track individuals from their adolescence to their middle-age in order to figure out the long-lasting effect of characteristics and sports activities, and find that good sports activities engagement can be established in adolescence, maintained in people's daily lives, and finally influence their wellbeing before retirement.

\subsection{Limitations}

Although a relatively large sample $(\mathrm{N}=12,686)$ with a multi-wave data collection strategy was used to test all hypotheses, the current study still suffers some critical limitations. First, we cannot infer causal relationships among key variables based on this study, and therefore suggest future studies to conduct experiments to test the causality. Moreover, although a one-item scale is a common practice for researchers to collect data, it may limit the reliability of each measure. Therefore, we suggest future studies use triangulated measures of the same constructs in order to substantiate the reliability of results.

Besides, although most of hypotheses are supported in current studies, some relationships are not supported. For example, we do not find the significant relationship between light activity and life satisfaction. We believe that the results may be influenced by the physical constraints, since participants 
in our study scatter across different places in the United States. Future studies should rule out the influences of these intervening variables.

\section{Conclusions}

In the current study, using a large sample of participants from various social classes in the United States and a multi-wave data collection design of more than 35 years, we establish a theoretical model linking individuals' characteristics and sports activities engagement to their lifetime wellbeing, which includes both physical and mental health and subjective life satisfaction. Based on the conservation of resources theory, we suggest that some individuals' characteristics such as self-esteem and personal control could help individuals to grasp more resources from the environment by engaging in more sports activities, which contributes to their wellbeing after many years. We try to contribute to theories and sports engagement literatures by extending our research objects to a longer timeline across different life spans.

This study also has some policy implications. As more and more individuals have emphasized sustainable lifestyles that provide them with more energy to deal with fierce competition and stressful issues surrounding them, regular sports engagement could be one of several useful tools for people to work long and stay healthy. In the current study, we carefully analyzed different predictors of sports activities engagement in order to point out which kinds of people are more likely to engage in sports activities. However, we do not suggest that individuals without a high level of these characteristics should not maintain a healthy lifestyle. Instead, individuals should carefully look at their own preference and try to overcome the potential disadvantages these characteristics may bring them. As we mentioned before, a healthy sports engagement can help people maintain a healthy and sustainable state even after many years. Therefore, everyone should have their own sports activities so that they can harvest more benefits across different life spans. Moreover, since a good sports engagement could be an effective tool to stay healthy, the government and relevant organizations should give full attention to encourage individuals to participate in more well-organized activities. Some researchers especially find that country-level policies have significant influences on individuals' sports activities [32], while few have indicated which kinds of policies can have the most profound influences [33]. Future studies can also focus on this topic, in order to conduct more interesting studies.

Author Contributions: All authors were involved in preparing the manuscript. J.Z. and Q.Y. contributed to the design of the research framework and developed the methodology. G.X. constructed the empirical study and conducted data analysis. J.Z. and G.X. wrote the manuscript. All authors have read and agreed to the published version of the manuscript.

Funding: This project was supported by the Shanghai Key Lab of Human Performance (Shanghai University of Sport) under Grant No. 11DZ2261100.

Conflicts of Interest: The authors declare no conflict of interest.

\section{References}

1. Georgian, B.; Lorand, B. The influence of leisure sports activities on social health in adults. SpringerPlus 2016, 5, 1647-1654. [CrossRef] [PubMed]

2. Guo, Y.; Shi, H.; Yu, D.; Qiu, P. Health benefits of traditional Chinese sports and physical activity for older adults: A systematic review of evidence. J. Sport Health Sci. 2016, 5, 270-280. [CrossRef] [PubMed]

3. Chacón Cuberos, R.; Zurita Ortega, F.; Puertas Molero, P.; Knox, E.; Cofré Bolados, C.; Viciana Garófano, V.; Muros Molina, J.J. Relationship between healthy habits and perceived motivational climate in sport among university students: A structural equation model. Sustainability 2018, 10, 938. [CrossRef]

4. Castro-Sánchez, M.; Zurita-Ortega, F.; García-Marmol, E.; Chacón-Cuberos, R. Motivational climate towards the practice of physical activity, self-concept, and healthy factors in the school environment. Sustainability 2019, 11, 999. [CrossRef]

5. Schlechter, C.R.; Rosenkranz, R.R.; Milliken, G.A.; Dzewaltowski, D.A. Physical activity levels during youth sport practice: Does coach training or experience have an influence? J. Sports Sci. 2017, 35, 22-28. [CrossRef] 
6. Tian, L.; Li, Y.; Li, P.P.; Bodla, A.A. Leader-member skill distance, team cooperation, and team performance: A cross-culture study in a context of sport teams. Int. J. Intercult. Relat. 2015, 49, 183-197. [CrossRef]

7. Winzer, E.B.; Woitek, F.; Linke, A. Physical activity in the prevention and treatment of coronary artery disease. J. Am. Heart Assoc. 2018, 7, e007725. [CrossRef]

8. Loprinzi, P.D.; Frith, E. Protective and therapeutic effects of exercise on stress-induced memory impairment. J. Physiol. Sci. 2019, 69, 1-12. [CrossRef]

9. Hobfoll, S.E. Conservation of resources: A new attempt at conceptualizing stress. Am. Psychol. 1989, 44, 513-524. [CrossRef]

10. Hobfoll, S.E. The influence of culture, community, and the nested-self in the stress process: Advancing conservation of resources theory. Appl. Psychol. 2001, 50, 337-421. [CrossRef]

11. Jones, S.C. Self-and interpersonal evaluations: Esteem theories versus consistency theories. Psychol. Bull. 1973, 79, 185-199. [CrossRef] [PubMed]

12. Pate, R.R.; Trost, S.G.; Levin, S.; Dowda, M. Sports participation and health-related behaviors among US youth. Arch. Pediatr. Adolesc. Med. 2000, 154, 904-911. [CrossRef] [PubMed]

13. Ylöstalo, P.V.; Ek, E.; Laitinen, J.; Knuuttila, M.L. Optimism and life satisfaction as determinants for dental and general health behavior-oral health habits linked to cardiovascular risk factors. J. Dent. Res. 2003, 82, 194-199. [CrossRef] [PubMed]

14. Ebstrup, J.F.; Aadahl, M.; Eplov, L.F.; Pisinger, C.; Jørgensen, T. Cross-sectional associations between the five factor personality traits and leisure-time sitting-time: The effect of general self-efficacy. J. Phys. Act. Health 2013, 10, 572-580. [CrossRef] [PubMed]

15. Rhodes, R.E.; Smith, N.E.I. Personality correlates of physical activity: A review and meta-analysis. Br. J. Sports Med. 2006, 40, 958-965. [CrossRef]

16. Stephan, Y.; Boiché, J.; Canada, B.; Terracciano, A. Association of personality with physical, social, and mental activities across the lifespan: Findings from US and F rench samples. Br. J. Psychol. 2014, 105, 564-580. [CrossRef]

17. Rhodes, R.E.; Pfaeffli, L.A. Personality and physical activity. In The Oxford Handbook of Exercise Psychology; Oxford University Press: Oxford, UK, 2012; pp. 195-223.

18. Tolea, M.I.; Terracciano, A.; Milaneschi, Y.; Metter, E.J.; Ferrucci, L. Personality typology in relation to muscle strength. Int. J. Behav. Med. 2012, 19, 382-390. [CrossRef]

19. Spence, M. Signaling in retrospect and the informational structure of markets. Am. Econ. Rev. 2002, 92, 434-459. [CrossRef]

20. Pearlin, L.I.; Schooler, C. The structure of coping. J. Health Soc. Behav. 1978, 19, 2-21. [CrossRef]

21. Connelly, B.L.; Certo, S.T.; Ireland, R.D.; Reutzel, C.R. Signaling theory: A review and assessment. J. Manag. 2011, 37, 39-67. [CrossRef]

22. Brown, J.D.; Mankowski, T.A. Self-esteem, mood, and self-evaluation: Changes in mood and the way you see you. J. Personal. Soc. Psychol. 1993, 64, 421-430. [CrossRef]

23. Becker, E. The Birth and Death of Meaning, 2nd ed.; Macmillan: New York, NY, USA, 1971.

24. Leary, M.R.; Baumeister, R.F. The nature and function of self-esteem: Sociometer theory. Adv. Exp. Soc. Psychol. 2000, 32, 1-62.

25. Baumeister, R.F.; Campbell, J.D.; Krueger, J.I.; Vohs, K.D. Does high self-esteem cause better performance, interpersonal success, happiness, or healthier lifestyles? Psychol. Sci. Public Interest 2003, 4, 1-44. [CrossRef]

26. Heimpel, S.A.; Elliot, A.J.; Wood, J.V. Basic personality dispositions, self-esteem, and personal goals: An approach-avoidance analysis. J. Personal. 2006, 74, 1293-1320. [CrossRef] [PubMed]

27. Hjartaker, A.; Lund, E. Relationship between dietary habits, age, lifestyle, and socio-economic status among adult. Eur. J. Clin. Nutr. 1998, 52, 565-572. [CrossRef]

28. Rosenberg, M. Society and the Adolescent Self-Image; Princeton University Press: Princeton, NJ, USA, 1965.

29. Baron, R.M.; Kenny, D.A. The moderator-mediator variable distinction in social psychological research: Conceptual, strategic, and statistical considerations. J. Personal. Soc. Psychol. 1986, 51, 1173-1182. [CrossRef]

30. MacKinnon, J.G. Bootstrap inference in econometrics. Can. J. Econ. 2002, 35, 615-645. [CrossRef]

31. Hayes, A.F. Beyond Baron and Kenny: Statistical mediation analysis in the new millennium. Commun. Monogr. 2009, 76, 408-420. [CrossRef] 
32. De Bosscher, V.; De Knop, P.; Van Bottenburg, M.; Shibli, S. A conceptual framework for analysing sports policy factors leading to international sporting success. Eur. Sport Manag. Q. 2006, 6, 185-215. [CrossRef]

33. Bergsgard, N.A.; Norberg, J.R. Sports policy and politics-the Scandinavian way. Sport Soc. 2010, 13, 567-582. [CrossRef]

(c)

(C) 2020 by the authors. Licensee MDPI, Basel, Switzerland. This article is an open access article distributed under the terms and conditions of the Creative Commons Attribution (CC BY) license (http://creativecommons.org/licenses/by/4.0/). 